\title{
Working at Their Full Potential: The Impact of the AMS Birman Fellowship
}

\section{Scott Hershberger}

One hundred fifty-nine men. One woman. Such was the gender breakdown of the faculty of Stevens Institute of Technology when Joan Birman became an assistant professor of mathematics there in 1968. Three years later, she arrived at Princeton University as a visiting assistant professor mere days before the first woman to earn a PhD in mathematics at Princeton departed for a job.

In the decades since, the representation of women at all levels of mathematics education and research has improved. But gender gaps persist: At US four-year colleges and universities, women make up $32 \%$ of all full-time mathematics and statistics faculty and hold $23 \%$ of tenured positions; in mathematics departments at $\mathrm{PhD}$-granting institutions, those figures fall to $24 \%$ and $15 \%$, respectively [1]. (Across all science, engineering, and health disciplines, by comparison, women occupy $38 \%$ of faculty positions and $31 \%$ of tenured positions at four-year colleges and PhD-granting institutions [2].) And even when women do attain faculty positions, they often face challenges that their male colleagues do not.

Blatant discrimination against women mathematicians, while on the decline, still hinders the progress of some in the field. Others experience indirect slights that accumulate over time, as their contributions to research, teaching, and community-building tend to be undervalued or overlooked. And outside of work, women are more likely than men to spend substantial time caregiving for relatives [3]. All these factors can diminish the amount of time and energy that women are able to dedicate to research.

Scott Hershberger is the communications and outreach content specialist at the AMS. His email address is $\mathrm{s} 1 \mathrm{~h} @ a \mathrm{ams}$. org.

For permission to reprint this article, please contact: reprint-permission aams.org.

DOI: https://dx.doi.org/10.1090/noti2439
According to Birman, for those who plan to have children, the most prominent obstacle is that "women's biological clock is very different from that of men." The birth of a child often coincides with a critical professional juncture. In 1970, the average age of first-time mothers in the US was 21. By 2016, it had risen to 26. Among college-educated women it had reached 30, an age at which mathematicians following a typical path are working in a post-doctoral or early tenure-track position [4], [5]. "A woman mathematician's instincts may tell her that attention not given to her children when they are infants may be irreplaceable, whereas time lost to mathematics can be made up later," Birman says. "Unfortunately, the mathematical community has tended to judge such decisions harshly, concluding that the woman slowed down because she was lacking in drive and in scholarship."

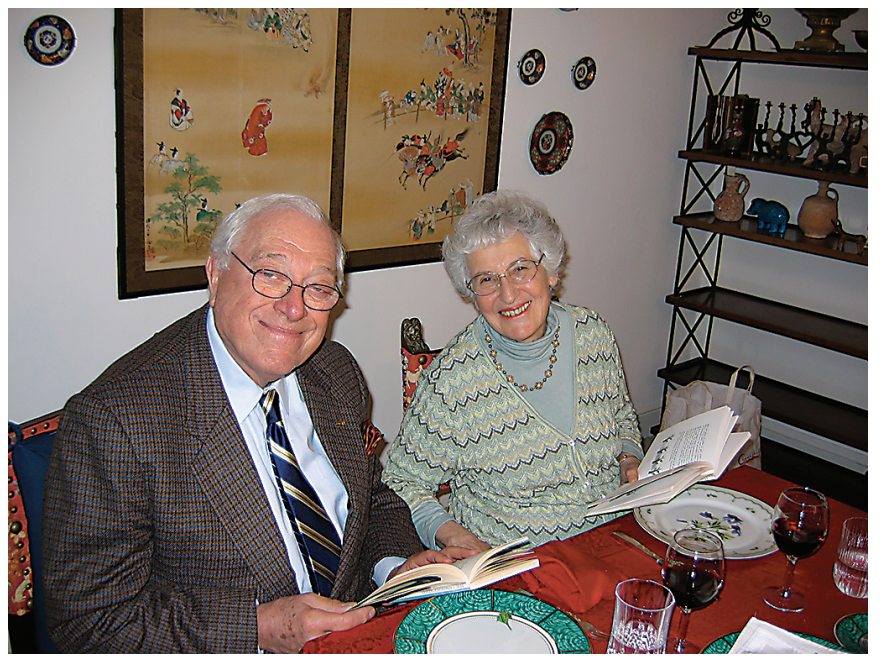

Joseph and Joan Birman in 2008. 
Birman herself followed a nontraditional path in the field (which she does not recommend). After receiving her bachelor's degree, she worked in industry, married, and had three children before returning to graduate school in mathematics. With her husband Joseph on the faculty at New York University, she received free tuition, and the couple could afford to hire babysitters so that Joan could take classes part-time. After passing her qualifying exams, she received a fellowship that enabled her to focus full-time on her dissertation.

Today Birman is well known for her pioneering work on braids and knot theory. Among her numerous recognitions, she was elected last year to the National Academy of Sciences. Her intellect, passion, and perseverance were key to her success. But she remains humble, acknowledging that in her early- and mid-career years, she received a level of support from her husband and male mathematicians such as Wilhelm Magnus, Ralph Fox, and Lipman Bers that was uncommon for women in mathematics in earlier generations.

After retiring, Birman sought to give back and lift up a new generation of women mathematicians. In 2017, she and her husband established the AMS Joan and Joseph Birman Fellowship for Women Scholars. The annual \$50,000 fellowship gives mid-career mathematicians extra research support. Crucially, the application process takes personal circumstances into consideration to ensure that the fellowship will make a real difference in recipients' trajectories.

So far, four mathematicians have been awarded Birman Fellowships. True to Joan Birman's goal, all have had exceptional research records but faced unique obstacles. "The first four awardees were just terrific. They were exactly the kind of candidates that Joe and I had in mind," she says. With the fellowship, they could handle life's hurdles, both expected and unanticipated, while carrying out ambitious research plans.

Lillian Pierce, the 2019-2020 Birman Fellow, spent some eight years either pregnant or nursing during the first decade of her career. She likens the long-term effect on her mathematics research of being a gestational parent to running a marathon while carrying an enormous pack. "The marathon is hard enough. A fellowship like the Birman can make a huge difference," she says. "Using its flexible resources allows women to creatively outsource the weight of that enormous pack and get back to running the marathon in a way that shows their full strength."

\section{A Change of Plans}

When applications opened for the inaugural Birman Fellowship, Margaret Beck was nearing a sabbatical semester. She wanted to extend the sabbatical to last a full year, but to do so she needed funding for the second semester. So she applied, not expecting anything to come of it.

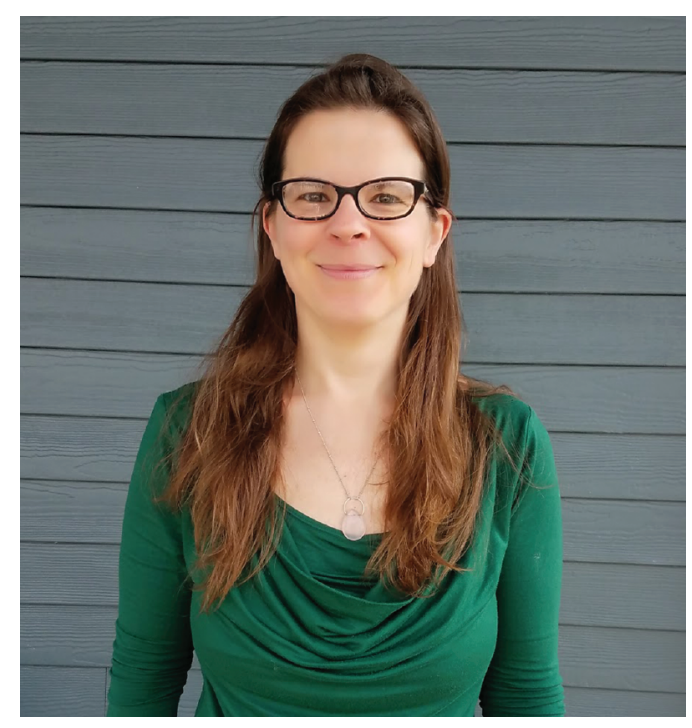

Margaret Beck, the 2018-2019 Birman Fellow.

At the time, Beck was an associate professor at Boston University. Studying dissipative partial differential equations, she was interested in exploring how a model's topological features can affect the stability of its solutions. When she found out that she had won the fellowship for the 2018-2019 academic year, "I was happily shocked and really excited."

Beck spent the fall 2018 semester as a research professor at the Mathematical Sciences Research Institute. "It was great. I got a lot done that semester," she says. "It was really nice to be away in a new environment where I wasn't as distracted by either everyday things in my home department or everyday things at my house." Meanwhile she was looking forward to the spring semester, which she planned to spend in Australia collaborating with Robert Marangell at the University of Sydney.

But while still in Berkeley, Beck had to take her oneyear-old daughter Esme to the emergency room. Esme was diagnosed with a rare condition whose treatment required medicine that was new, expensive, and difficult to obtainruling out travel to Australia. Instead, Beck returned with her daughter to Boston, still planning to collaborate with Marangell as best she could remotely.

Unfortunately, life interfered once again when her mother fell deeply ill. Beck spent the majority of the semester with her and remembers being "terrified" that she would need to return the fellowship money. But supporting women through career disruptions is the point of the fellowship. Built into it is the flexibility to adapt to changing circumstances. Joan Birman reiterates that the selection committee "got everything right."

"I honestly don't know what I would have done if I hadn't been on the fellowship," Beck says. "If I'd been teaching two classes and trying to be with my mother, I really 
have no idea how that would have worked." Although her year did not go according to plan, the fellowship "enabled me to survive during that time, and it enabled my research to survive-even though it was on pause."

The following summer, Beck attended mathematics conferences alone for the first time since the birth of her daughter. And during the pandemic, Esme's father was a stay-at-home dad, giving Beck time to dive back into research. Among other projects, she resumed her remote collaboration with Marangell. The two are studying the Maslov index, a topological invariant connected with stability problems in partial differential equations. Last year, Beck was promoted to a full professor in recognition of her continuing excellence in research.

\section{"The Mountain We Needed to Climb"}

Many mathematicians attribute their trajectory in the profession to the influence of a particularly inspiring mentor. For Lillian Pierce, that mentor was Elias Stein, a harmonic analyst at Princeton who was her first college mathematics professor and her PhD advisor. Stein taught and wrote about mathematics with patience, high standards, and clarity, Pierce says, and without him she would not be a mathematician. "It would be hard to overstate the impact that Eli has had on my time in mathematics."

As Pierce began her career, analysis and number theory often seemed to be treated as separate disciplines. But Pierce saw more connecting the two than isolating them, and she spent her post-doctoral years exploring those links.

In 2018, she became the Nicholas J. and Theresa M. Leonardy Associate Professor of Mathematics at Duke University. Still actively collaborating with Stein, Pierce embarked with him on a project to write the first book on discrete operators in harmonic analysis. When she applied to the Birman Fellowship in late 2018, she had three children, including a nursing infant. She proposed to use the funds to fly frequently for short visits with Stein to accommodate his age and her children. But then, in December of that year, Stein passed away from lymphoma.

As Pierce mourned her friend, mentor, and collaborator, the fellowship committee wrote to her, asking if she wanted to reframe her application. "I had an instantaneous feeling that my application had crumbled, and I accepted that," she says. But further reflection helped her see how the fellowship could still benefit her long-term plans. She proposed using the funds to buy out teaching so she could focus on the book, and to fly collaborators to visit her so that she would not have to leave her children as often.

With no teaching, the first semester of the fellowship was "rejuvenating," Pierce says. "I tackled a series of chapters in the middle of the book that Eli had referred to as the mountain we needed to climb. I was back to full speed on the project."

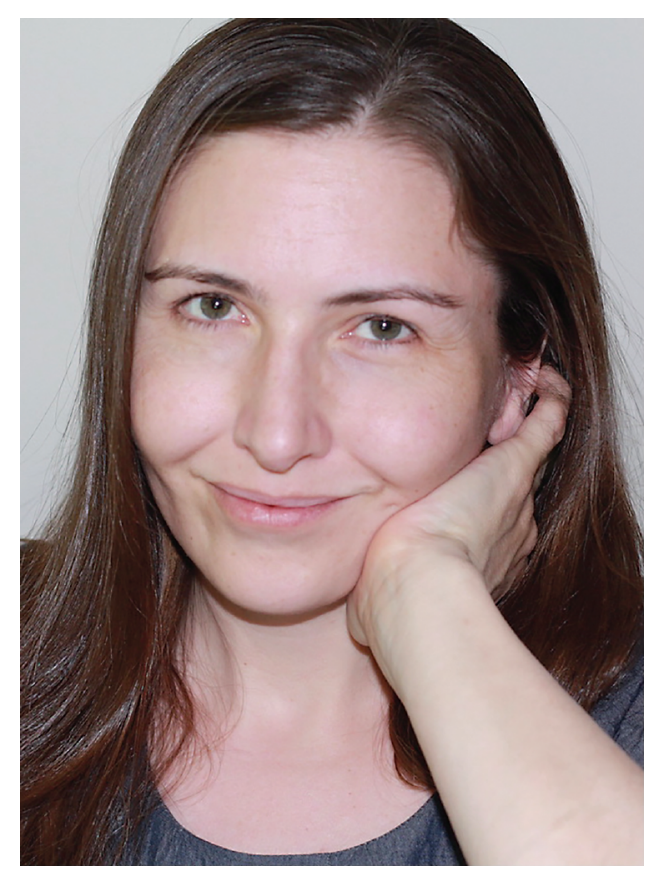

Lillian Pierce, the 2019-2020 Birman Fellow.

One concept that Pierce explored during that time was "superorthogonality," which generalizes orthogonality from pairs of functions to any even number of functions. Building on her collaboration with Stein, she studied five types of superorthogonality, finding unexpected connections between current problems in analysis, number theory, and even algebraic geometry.

When the pandemic hit, Pierce had not yet taken the research trips that she had planned. The flexibility of the Birman Fellowship allowed her to postpone using the remaining funds. And in a year when optimism was hard to come by, the fellowship continued to help her. "I'm remembering the lesson that when external circumstances improve, I will again be able to work at my full potential," she says. "I feel extremely lucky to have had this generous, flexible fellowship buoying me during this time period."

Now a full professor, Pierce looks forward to finishing the book. And as travel becomes possible again, she will use the remainder of the fellowship funds for visits with collaborators.

\section{A Long-sought Proof}

While the pandemic impacted the tail end of Pierce's fellowship, it left a mark on Karin Melnick's entire fellowship year. Melnick, an associate professor at the University of Maryland, College Park, works on differential geometric aspects of rigidity and has long been interested in the Lorentzian Lichnerowicz conjecture, a statement about conformal transformations of compact Lorentzian manifolds.

Melnick won the AMS Centennial Fellowship for the 2012-2013 academic year and received tenure in 2014. 
Three years later she had a baby. Caring for her child "took away from the time that I had for work, though certainly my colleagues were supportive," she says. "I just didn't have as much time to do research."

As her baby became a toddler, Melnick began ramping up her research again and finished a major project. She applied for the Birman Fellowship with the goal of continuing to build that momentum through research travel and course buyouts. But COVID-19 forced her to scrap plans to visit collaborators. Instead, she bought out an additional course, eliminating her teaching load entirely for the fall 2020 semester. That opportunity proved even more valuable than in a typical semester, since "I was spared some of the chaos" of online teaching, she says. While working virtually with collaborators, she reached a milestone in her work. As her fellowship year drew to a close, she neared completion of a proof of the Lichnerowicz conjecture for 3-dimensional manifolds, valid under certain minor assumptions.

"This would be the first time it's been proved in a given dimension," she says. "It feels very good. It's exciting because it gives some encouragement that the general conjecture is really true, and it could be that we're closer to having the tools to prove it."

An unexpected benefit of the fellowship was a new friend. When Melnick's award was announced, Pierce reached out to her to offer congratulations. The number theorist and the geometer found that they had other things in common, sparking a longer email conversation. "That meant a lot to me," Melnick says.

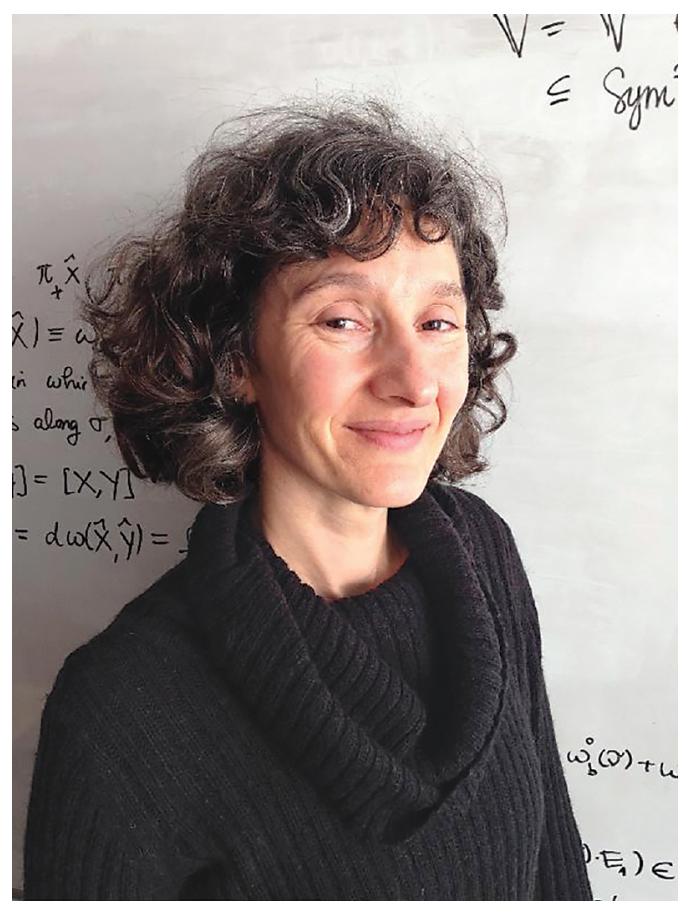

Karin Melnick, the 2020-2021 Birman Fellow.
In the future, she hopes to keep working on the Lichnerowicz conjecture while expanding into new areas. One of her new projects stems from the Zimmer program, which seeks to understand the actions of large semisimple Lie groups and their discrete subgroups on smooth manifolds. Melnick is classifying certain actions in this context and also wants to understand when these actions preserve differential geometric structures.

Melnick says that the boost provided by the fellowship will benefit her research career for years to come. "It's not just another star on the $\mathrm{CV}$, but also the confidence that comes from being recognized and the extra research time that comes from having money to buy out teaching."

\section{Unrecognized Work and Undervalued Contributions}

The first four recipients of the Birman Fellowship have experienced firsthand the challenges associated with being pregnant and raising children while pursuing mathematics research. They also point out that many other roadblocks still exist for women in the field.

Despite the advances of recent decades, some women still experience direct discrimination from other mathematicians. Beck occasionally finds herself providing support to graduate students whose male peers are treating them poorly. Carrying that weight can consume a lot of emotional energy, she says. But open discrimination is just one aspect of a subtler imbalance: "My feeling is that women are much more likely to take on the unrecognized work that has to be done in any department just to make things function well." Various forms of community-building work take away from the time Beck and others have to conduct their research. "I have many male colleagues who are wonderful, great people, but somehow, on average, I don't think the genders tend to do equal amounts of work in that regard," she says.

When it comes to research, too, women's talent and contributions are sometimes undervalued, Melnick says. "I think [this occurs] maybe because of a shortage of role models or because of the dynamics of how mathematicians interact with each other and assess each other," she says. "It's unfortunately possible for especially younger female mathematicians to undervalue their own talent." A similar bias extends to students' perceptions of their professors: In course evaluations on RateMyProfessors, female mathematics professors are praised as "brilliant" or "genius" about $40 \%$ as often as their male colleagues [6].

The factors pushing women away from careers in mathematics begin early in life. According to Helen Wong, the current Birman Fellow, the typical experience of a student-attending lectures, completing homework, and taking exams-emphasizes individual work, often resulting in a misunderstanding about the nature of mathematics research. "People don't realize that collaboration is so 


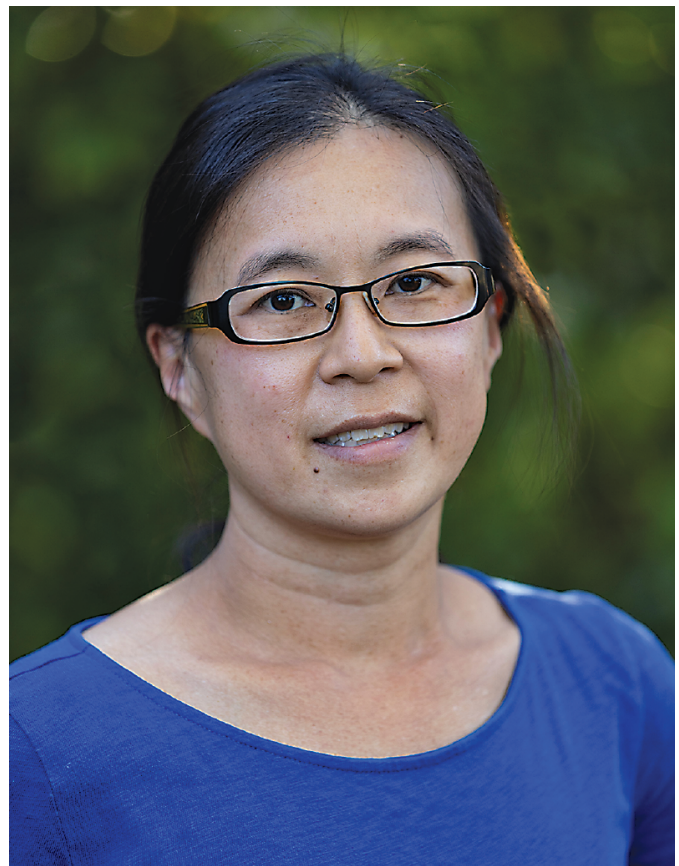

Helen Wong, the 2021-2022 Birman Fellow.

prevalent and so important in mathematics, and women from the get-go are turned off by the idea of working alone," Wong says.

On top of it all, studies show that the negative impact of the COVID-19 pandemic on researchers has been disproportionately felt by women, especially mothers. By the summer of 2020, single mothers in academia lost an average of 90 minutes of research time per day, compared to an average loss of 60 minutes per day for single fathers [7]. The effects of this lost time will compound in the coming years, underscoring the importance of awards like the Birman Fellowship for mathematicians whose personal circumstances hinder their research aspirations.

\section{Moving Forward After a Pandemic Year}

In high school, Helen Wong didn't know that math beyond calculus existed. As an undergraduate, she considered majoring in chemistry, economics, and even music. But a summer mathematics program at the University of California, Berkeley revealed the joys of a career in mathematics and introduced her to topology, the subject she fell in love with. Wong earned her $\mathrm{PhD}$ in mathematics from Yale University in 2007 and is now an associate professor at Claremont McKenna College.

For Wong, receiving a fellowship named for Joan Birman is meaningful on multiple levels. In addition to being inspired by Birman's life story, Wong refers to Birman's results on braid groups often in her own research. Wong studies quantum topology, examining invariants such as those related to the Jones polynomial or Witten-Reshetikhin-Turaev quantum field theory. Her work has potential applications to quantum computation, where the motion of anyon qubits can be viewed through the lens of braid theory. In another project, Wong is working with biophysicists to analyze how proteins and DNA become knotted.

In March 2020, Wong suddenly found herself supervising Zoom school for her two daughters, then in preschool and 1 st grade. She and her husband, a biostatistician, both had full-time jobs, and "there was no way that we could both work 9 to 5 and make sure the kids were okay." The parents did their best to share household duties, but both saw their research suffer. And on top of childcare, the shift to online instruction forced Wong to spend extra time and energy overhauling the classes she was teaching.

"Luckily, I had research collaborators that were basically in the same boat. They all had little kids at home," Wong says. Occasional meetings served to keep the thread of research alive, even if no one had time to make progress between meetings.

Like Beck, Wong did not think she had much of a chance to receive the Birman Fellowship-she only applied because her college encouraged her to do so. She had similar doubts about the Simons Fellowship, yet she received both awards for the 2021-2022 academic year. "I want to encourage women to apply for things even though they feel like they're not qualified," Wong says. During her fellowship year, she aims to resume her research with undergraduates as well as fly to visit collaborators on other projects. Although she loves teaching, she is using the fellowship to buy out her spring courses in order to create a year focused on research.

For Beck, Pierce, Melnick, and Wong, the Birman Fellowship is just the latest manifestation of support-whether institutional, financial, familial, or from colleagues-that has eased the burden of their proverbial packs and buoyed their careers in mathematics. While money alone cannot eliminate all the obstacles faced by women mathematicians, the early success of the fellowship makes Birman optimistic about its long-term impact: "I believe that, after enough time, and especially if it attracts additional support, the Birman Fellowship for Women Scholars stands a chance to make a real contribution to the matter of the paucity of women at the top levels of research in mathematics."

\section{References}

[1] A. Golbeck, T. Barr, and C. Rose, Fall 2018 Departmental Profile Report, Notices Amer. Math. Soc. 67 (2020), 16151621.

[2] National Center for Science and Engineering Statistics, Women, Minorities, and Persons with Disabilities in Science and Engineering: 2021, Special Report NSF 21-321, Alexandria, VA: National Science Foundation, last visited July 23, 2021. https://ncses.nsf.gov/wmpd

[3] AARP and National Alliance for Caregiving, Caregiving in the United States 2020, AARP, May 2020, last visited August 13, 2021. https://doi .org/10.26419/ppi .00103.001 
[4] Q. Bui and C. C. Miller, The Age That Women Have Babies: How a Gap Divides America, The New York Times, Aug. 4, 2018, last visited June 23, 2021. https://www. nytimes .com/interactive/2018/08/04/upshot/up-birth-age -gap.htm 1

[5] A. Golbeck, T. Barr, and C. Rose, Report on the 2017-2018 Employment Experiences of the New Doctoral Recipients, Notices Amer. Math. Soc. 67 (2020), 1207-1213.

[6] D. Storage, Z. Horne, A. Cimpian, and S. J. Leslie, The Frequency of "Brilliant" and "Genius" in Teaching Evaluations Predicts the Representation of Women and African Americans across Fields, PLOS ONE 11 (2016), no. 3, last visited June 23, 2021. https://doi.org/10.1371/journal .pone.0150194

[7] T. Deryugina, O. Shurchkov, and J. E. Stearns, COVID-19 Disruptions Disproportionately Affect Female Academics, National Bureau of Economic Research, Working Paper 28360 (2021), last visited June 23, 2021. https://www .nber.org/papers/w28360

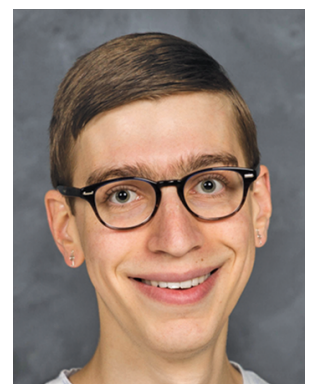

Scott Hershberger

\section{Credits}

Photo of Joseph and Joan Birman is courtesy of Beth Birman. Photo of Margaret Beck is courtesy of Greg Blotzer. Photo of Lillian Pierce is courtesy of Lillian Pierce. Photo of Karin Melnick is courtesy of A. Chatzistamatiou. Photo of Helen Wong is courtesy of Claremont McKenna College.

Author photo is courtesy of Jiyoon Kang.

\section{About the Birman Fellowship}

The Joan and Joseph Birman Fellowship for Women Scholars seeks to address the paucity of women at the highest levels of research in mathematics by giving exceptionally talented women extra research support during their mid-career years. The most likely awardee is a mid-career woman, based at a US academic institution, with a well-established research record in a core area of mathematics. The fellowship will be directed toward those for whom the award will make a real difference in the development of their research career. Special circumstances may be taken into consideration in making the award.

Learn how to apply at https://www. ams . org/Birman -fellow.

\section{About the Birman Fund}

Established in 2017 with a generous gift from Joan and Joseph Birman, the Birman Fund is an endowed fund that supports the Birman Fellowship. Gifts to the Birman Fund will help the AMS continue to offer this fellowship in the future and ensure that it remains one of the premier fellowships for women mathematicians.

You can donate to the Birman Fund by visiting https://bit.7y/3FLVLEM or by sending a check to the AMS Development Department with instructions to direct the gift to the Birman Fund. You can also call the Development Office directly to discuss other options for giving.

201 Charles Street

Providence, RI 02904

Phone: 401-455-4111 